\title{
Competences as Seen by Teachers and Employers in an Initial Vocational Training Reform*
}

\author{
Raymond Meyers, Anne Pignault, Claude Houssemand \\ University of Luxembourg, Esch-sur-Alzette, Luxembourg
}

\begin{abstract}
Luxembourg has a dual system of initial vocational training, inspired by the German model, where training takes place alternately in enterprises as well as in schools. Since 2008, a competence-based reform of vocational training is being implemented in the upper level of secondary education in Luxembourg. Semi-structured interviews were carried out with the relevant actors to analyse their strategies and perspectives during and after the reform. It appears that one major difficulty in the implementation of the reform is the difference between schools' and enterprises' understanding of what competence-based training is. The majority of teaching staff disagreed with training through competences as it was considered a more difficult and less manageable approach for them than previous knowledge-based methods. When they adopt the prescribed approach albeit reluctantly, they often attribute it a meaning which is mostly school-based, where competences are seen as skills in exercises based on books and programs and not in professional situations. Enterprises were in favour of curricula based on competences, as they are more suited to the practical work expected in the professional domain. Pupils are confronted directly with practical professional situations at the workplace, but enterprises have problems in implementing explicit, systematic and progressive modular training. Coordination between these two main actors in the training system is poor and problematic; especially with regards to collaboration within the curriculum teams that are expected to develop and update the training modules. A general fatigue with the reform has spread, even if most actors agree, at least verbally, with its general philosophy; and this at a moment when the Ministry wants to implement new changes to the law. In order to make the reform viable, a newly negotiated agreement based on the interests of the different players, especially between enterprises and schools, should be achieved.
\end{abstract}

Keywords: competences, vocational training, secondary education, interviews

\section{Introduction}

Traditionally, Luxembourg has had a dual system in initial vocational training. This is inspired by the German model, where alternating training takes place in enterprises as well as in schools (Noesen, 2005; Refernet, 2015). Vocational education is a very complex matter due to the multitude of actors involved (mainly schools, enterprises, professional Chambers with their apprenticeship advisers) and the low-achieving student population involved. Most professional qualifications are obtained via an alternating system with three to four days

\footnotetext{
*Acknowledgements: The study was supported through a grant from the Ministry of Education of Luxembourg. We would like to thank Mary Devine for the linguistic revision of the text.

Raymond Meyers, Ph.D., Senior lecturer, Institute of Lifelong Learning and Guidance (LLLG), University of Luxembourg. Anne Pignault, Ph.D., associate professor, Institute of Lifelong Learning and Guidance (LLLG), University of Luxembourg. Claude Houssemand, Ph.D., professor, Institute of Lifelong Learning and Guidance (LLLG), University of Luxembourg.
} 
on-the-job training in companies. Since 2008, a reform of vocational training is being implemented in the upper level of secondary education in Luxembourg (MENFP, 2011a; 2011b). The new method consists mainly of teaching through competences instead of through knowledge transfer as was the case before (MENFP, 2008). The reform continues to face challenges and criticisms from the different actors involved in vocational training. In 2014, changes were planned in order to revise the former reform, leading to a new bill submitted to Parliament in the year 2015 (MENJE, 2015).

\section{Objectives}

This study used qualitative interviews and a methodology in line with the assumptions of interpretive social science (Neuman, 1997). Semi-structured interviews were carried out with the relevant actors in order to analyse their strategies and perspectives during and after the reform to today. We interviewed professional Chambers who represent employees and business owners, teachers, school heads, apprenticeship advisers, parents and students. These results were already presented (Houssemand, Pignault, \& Meyers, in press), but we want to take a different approach here and to focus mainly on the two most relevant actors, the school teachers and the companies and how they each understand and practice competence-based training.

\section{Results}

It appears that one major difficulty in the implementation of the reform is the difference between schools and enterprises in their understanding of a competence-based training. This disparity is due to big differences in the contexts of training, and also to the differing learning traditions and professional profiles of school teachers and of enterprise trainers. It is of course not the only problem of the reform, but we are going to focus on it in this text.

\section{Enterprises}

Businesses were in favour of a curriculum based on competences, as they are more suited to the practical work carried out in the professional domain. Moreover, new skills and competences are necessary in a changing economy. Hence businesses were looking for an increased range of skills from a low-achieving apprentice population. Enterprises and their representatives, the Chambers, are also looking for a better orientation and a better level of lower secondary education, which would allow them to recruit more motivated and more skilled pupils at the entry of vocational training, especially for apprenticeships.

While enterprises were, in principle, positive towards the reform, they also had difficulties with the abstract and systematic formulation of training modules, which was asked for by the reform. Before the reorganization, training at the work place was mostly done in a non-systematic manner, mainly consisting of on-the-job initiation making use of the jobs at hand. The new modular approach asked for a systematic progression of increasing difficulty through skills acquisitions which are centred on specific objectives. These are supposed to be achieved, evaluated and integrated in a coherent set, which would be the specific competences profile of the relevant profession. Training for trainers was developed, but it did not include the evaluation of apprentices. The new competence-based evaluation, especially the "integrated" evaluations, which are supposed to evaluate if the apprentices are able to make a synthesis of different learnings, are taking place at mid-term and at the end of the training period, and are perceived to be difficult to organise by companies, because it interrupts the normal business as usual. 


\section{Teachers}

The context of training is radically different for teachers than for trainers in enterprises. Even if there are workshops for certain branches, teaching is mostly classroom-based, and hence has little direct contact to the professional world. Therefore, the majority of teaching staff was in fact against training through competences as it was considered a more difficult, less manageable approach than the previous knowledge-based methods. Evaluating competences, in the sense of a contextualised skill taking into account the complexity of professional context, appears more difficult than evaluating knowledge which is in a book. During their initial training at university, future teachers are also not well prepared for work at vocational schools. Specifically, preparation for teaching a competence-based training is absent. They are trained in knowledge-based contents like literature, mathematics or physics rather than delivering content in an on-the-job design. It is also a reality that teachers in Luxembourg are concerned about their classroom-based autonomy. Traditionally, school-based curricula consisted of chapters of printed manuals completed by exercises. In certain branches, these matters were accomplished by workshop practice, not necessarily linked to practical professional situations, as was the case in the companies where pupils had to do their work-based curriculum.

When they reluctantly adopt the prescribed approach, they often give it a meaning which is mostly school-based, where competences are seen as skills in exercises based on books rather than on professional realities. The ambiguity and polysemy of the concept of competence is also responsible for a school-based rather than a professional understanding of training. For example, Rey, Caffieaux, Defrance, and Marcoux (2005), in an attempt to clarify the concept, distinguish between three levels of competences. The first one is the routinisation of elementary cognitive skills, like the multiplication tables. The second one is having at one's disposal a whole set of these basic skills and to be able to choose between them, the most appropriate one. The third consists of choosing and combining several basic skills in order to treat a new and complex problem. As this typology shows, every skill can be understood as a competence without having to leave the school context. This allows teachers to adapt at a superficial level to the new competence-based approach, but to continue to teach in a similar way as before. They also often implicitly kept the evaluation system by points, translating it into competence-based evaluation on paper.

\section{Transversal Actors: Curriculum Teams}

The new curricula were supposed to be written by teams comprising representatives of teachers, employees, entrepreneurs, and professional Chambers of both employees and business owners. When the reform was first launched, most of the competence-based modules were not complete, and some remain so today. These modules were produced, often very late, and with very different levels of quality or difficulty depending on the profession or the module. The whole architecture of the training modules is also poorly constructed. Modules appear often as independent and not as articulated building blocks of a whole, which is particularly problematic from a competence-based training perspective.

Additionally, the teams did not work together well due to differences in the professional profiles of their members. Teachers were perceived as too intellectual, to "verbal" and not practical enough; whereas representatives of the businesses often found it difficult to contribute to discussions about teaching objectives and how to achieve them, a discussion which they often perceived to be very abstract. Company representatives had problems with time investment and lack of remuneration, whereas with teachers, meeting times are considered as part of their working time and hence remunerated. The teams were also left to themselves, except for some scant 
follow-up by foreign educational experts who were perceived to be too theoretical. Without specific preparation and professional support to the teams, it is unlikely that a coherent quality product will be produced. There was no general work plan and no follow up of the teams which could have contributed towards coherence and homogeneity in the design of training modules, at least for professions of similar complexity.

\section{Conclusions}

The project of the reform of initial vocational training was to replace knowledge-based education by a generalised competence-based curriculum, and to make progression through training modules very individualised. Several years after the implementation of the reform, it has not yet reached its objectives. A general fatigue with the reorganization has spread, even if most of the actors agree at least verbally with its general philosophy; and this at a moment when the Ministry has issued a new bill in order to implement new changes to the aforementioned law (MENJE, 2015). Our results are not new (Ropé \& Tanguy, 1994), showing that schools and enterprises have differing notions on what a competence is.

In order to make the reform viable, a new negotiated agreement based on the interests of the different players, like proposed by sociology of organisations (Dupuy, 2004), should be elaborated if the reform is to have a chance of being viable. But the main issue, the replacement of a knowledge-based educational system with competence-based training is unlikely to be solved by the ongoing "reform of the reform" (MENJE, 2015), unless a real agreement between schools and enterprises is found concerning the implementation and the updating of the training modules as well as on a fruitful collaboration between the two most relevant partners. This could be achieved specifically through well-organised and supervised curriculum teams.

\section{References}

Dupuy, F. (2004). Sociologie du changement. Paris: Dunod.

Houssemand, C., Pignault, \& Meyers, R. (in press). Strategies and perspectives of school actors during a reform of vocational training in Luxembourg. Global Journal on Social Sciences and Humanities.

MENFP. (2008). Loi modifiée du 19 décembre 2008 portant réforme de la formation professionnelle. Luxembourg: Mémorial.

MENFP. (2011a). Berufsbildung neu gestalten: Entwicklung von modularen und kompetenzorientierten Ausbildungsgängen. Luxembourg: MENFP.

MENFP. (2011b). Recueil des outils pour la réforme à l'usage des enseignants et des formateurs en entreprise. Luxembourg: MENFP.

MENJE. (2015). Projet de loi portant modification 1) de la loi modifiée du 19 décembre 2008 portant réforme de la formation professionnelle, 2) de la loi du 15 Juillet 2011 visant l'accès aux qualifications scolaires et professionnelles des élèves à besoins éducatifs particuliers, 3) de l'article L.222-4 du Code du Travail. Luxembourg: MENJE.

Neuman, W. L. (1997). Social research methods: Qualitative and quantitative approaches. Needham Heights, M.A.: Allyn \& Bacon.

Noesen, J. (2005). La formation et l'enseignement professionnels au Luxembourg: Une brève description. Luxembourg: Office des publications officielles des Communautés européennes.

Refernet. (2015). Luxembourg: VET in Europe-Country report 2015. Luxembourg: Refernet CEDEFOP.

Rey, B., Caffieaux, C., Defrance, A., \& Marcoux, G. (2005). L'articulation entre savoirs et compétences dans l'enseignement secondaire. Bulletin d'Informations Pédagogiques, 57, 3-14.

Ropé, F., \& Tanguy, L. (Eds.) (1994). Savoirs et compétences: De l'usage de ces notions dans l'école et l'entreprise. Paris: L'Harmattan. 